\title{
GMO Labeling: A Case of Asymmetric Information and the "Nudge"
}

\author{
By Katherine Hartman
}

From their introduction in the late 1990s, foods containing genetically modified organisms (GMOs) have sparked debate among advocates and policymakers. To correct information asymmetry inherent in the current system of selling genetically modified (GM) and nonGM foods alongside each other with no consistent signal of quality across food products, many have suggested-and the European Union and Japan have implemented-labeling regimes. This paper takes the position that consumers' empirically supported desire (for reasons ranging from nutritional to religious) to avoid GM goods substantiates a market failure resolvable through information provision. Then, it examines labeling through Akerlof's "Lemons" model and the behaviorist concept of the "nudge." It concludes that mandatory labeling would maximize social welfare, enabling informed purchasing for all consumers (notonly thosewhoshop atmore expensive grocers initiating private labeling). Finally, the paper discusses labeling regime implementation-including label design, product purity baseline setting, administration, and consequences.

\section{Introduction}

From the initial introduction of foods containing GMOs into the mainstream food supply in the 1990 s, there has been a steady debate regarding the implications of GM food and the best ways to promote consumer well-being surrounding food purchasing choices. This paper will first describe the recent discussions of GMOs and GMO labeling; it will then examine arguments both for and against mandatory labeling mechanisms. Finally, the paper will consider the labeling issue through the dual lenses of information asymmetry (as described by Akerlof) and libertarian paternalism (as described by Thaler and Sunstein). Throughout, the paper references the European market, where GMO labeling is already commonplace. While the European and the US food markets operate in different contexts (with European consumers spending higher proportions of their incomes on food), the European market is likely the best existing baseline comparison for purposes of this analysis.

The policy recommendation, based on these concepts, will be for a government-administered mandatory labeling system; the paper will also discuss the negative implications of such a system, which include shifts in consumer and producer incentives and preferences, as well as potentially disproportionate burdens on low-income populations.

The recommendation of a mandatory, as opposed to voluntary, system is based on the mandatory regime's ability to provide meaningful, actionable information with overarching, market-wide governmental oversight and enforcement across food products and brands in ways that ad-hoc voluntary labeling with inconsistent-atbest oversight could not. Additionally, the 
mandatory regime would optimize social welfare by allowing all consumers to make informed purchasing decisions. In its provision of information to all consumers, the label also addresses negative distributional implications of the current system in which only affluent consumers are able to avoid GMOs by shopping at more expensive boutique grocers.

\section{GMOs and Recent Labeling Scheme Proposals}

GMOs have been controversial since their integration in the mainstream food supply late in the last century. "The term genetically modified organism (GMO) specifically describes a type of genetic modification in which the DNA [...] of microbes, plants, and animals is directly altered [. . . ] Unlike genetically modified (GM) products in the pharmaceutical sector, such as insulin, GMO food and animal products [... .] are highly controversial on account of mutually overlapping concerns of health, environment, economics, and ethics" (Jain 2011, 217).

There are discrete markets for both GM and non-GM products: "about one-quarter of [consumers] are substantially indifferent, and the remainder displays demand that is decreasing in the GM content" (Lapan and Moschini 2007, 781). Those in favor of GMO use assert that the "technology raises harvest yields, reduces agrochemical use, and will eventually even produce high-nutrition food that can grow in depleted soil" by designing crops to be resistant to pests and other threats (Schmidt 2005, A527). They also suggest that although the idea of GM food is somewhat unpalatable to many Americans, there is little evidence of negative implications for consumer health related to the "nearly 45 percent of the corn and 85 percent of the soybeans grown in the United States [that] are transgenic" (2005, A531). Even the EU, which mandates GMO labeling, makes no quality or safety differentiation between GM and non-GM foods, acknowledging that "mandatory labeling is justified solely by the desire to provide informed consumer choice" (Carter and Gruère 2003, 68).

Those who are concerned about the health effects of GM food sources "counter that the risks of GM foodsmade with gene splicing methods from biotechnology-are unknown and poorly addressed by current testing methods" and cite risks of cross-pollination and contamination of the conventional seed supply (Schmidt 2005, A527). Indeed, that risk may already have become a reality: a 2004 report by the Union of Concerned Scientists found that "the seeds of traditional varieties bought from the same retailers used by US farmers are contaminated with low levels of DNA sequences originating in genetically engineered varieties of those crops" (Mellon and Rissler 2004, 1). In that study, the size of which the authors admit begets little external validity beyond an indication of generally low contamination levels, "[t]he most conservative expression of the combined results is that transgenically derived DNA was detected in 50 percent of the corn, 50 percent of the soybean, and 83 percent of the canola varieties tested" (2004, 1-2).

Such contamination may routinely go unnoticed, with potentially significant ramifications for consumers. In the US, only "crops that contain a pesticidal protein such as Bt toxin must undergo mandatory allergenicity testing coordinated by the Environmental Protection Agency" (Schmidt 2005, A532). Additional testing by the Food and Drug Administration (FDA) is voluntary. The concerns, which a label could alleviate, then, are twofold: the potential health risks and threats of conventional supply contamination. Each concern centers on threats to the ability of an individual to know and subsequently make consumption decisions based on food quality.

While the evidence for or against the health threats of GM foods is mixed, for purposes of this paper, foods con- 
taining GMOs will be considered to be inferior (the language Akerlof uses in his model) to GM-free foodstuffs because of this choice issue. The argument could very well be made that while there are substantive differences in quality between the goods in Ackerlof's model, that the differences in quality between GM and non-GM goods are unsubstantiated at best. The fact that relatively nascent (and perhaps not-yet-thoroughly-evaluated) bioengineering technology could lead to as-yet undiscovered ill health effects, however, underscores the importance of information provision in this case. Furthermore, the importance of knowing the contents of food being consumed for persons wishing to avoid certain foods due to ethically-, religiously-, health-based, and other dietary restrictions warrants disclosure of modification so that these persons can avoid unknowingly violating their dietary practices. Because GM foods are genetically different from their conventionally grown counterparts, consumers' current inability to choose in accordance with personal preferences-whether those preferences be based on health concerns, dietary habits and restrictions (some religiously based), or other criteria-reduces consumer welfare. Indeed, according to the text of the Washington State Initiative Measure No. 522, "Polls consistently show that the vast majority of the public, typically more than ninety percent, wants to know if their food was produced using genetic engineering. Without disclosure, consumers of genetically engineered food unknowingly may violate their own dietary and religious restrictions" (Washington State Initiative Measure No. 522).

To address the choice issue, numerous entities have proposed labeling schemes which would require producers of food products containing GMOs to label them explicitly as such. In November 2012, Californians voted against Proposition 37, which would have required producers of foods that are genetically engineered or contain GMOs to refor- mulate their packaging to communicate the presence of such ingredients. More recently, Washington State residents rejected a similar proposal in November 2013 after corporations concerned about price increases and consumer confusion "poured millions into the campaign against labeling" in the final weeks before a vote (Barclay and Kaste 2013).

Maine and Connecticut, however, have passed legislation requiring labeling, and in March 2013, Whole Foods Market announced mandatory labeling of GM products in its stores by 2018 . According to Whole Foods' president, A.C. Gallo, consumer demand at the store has fueled a manufacturer-reported " 15 percent increase in sales of products they have labeled" voluntarily as not containing GMOs (Strom 2013). The consumer demand for labeling at Whole Foods is possibly due to the customer base's greater interest in whole, i.e., non-modified/adulterated; organic; and nutritious food. That being said, the move-and the consumer demand to which it responded-represents a significant shift in the GMO labeling debate.

Other proposed labeling regimes have been presented on ballots in Missouri, Pennsylvania, and numerous other states, exemplifying the burgeoning nationwide grassroots movement to require labeling of GM products. This growing sentiment indicates that the time may have come for the US, like Europe and Japan, to respond to the "proponents of labeling [who] insist consumers have a right to know about the ingredients in the food they eat" (2013). To fully understand the positive and negative aspects of such an initiative, it is important to consider the economic arguments behind a labeling mandate.

\section{Economic Arguments For and Against a Labeling Mechanism}

The markets involved in a labeling mechanism are discrete yet related. They include the market for processed 
snack foods (those found on the inside aisles of grocery stores that would be required to disclose GMO ingredients on their packaging); non-organic, nonpackaged foods (specifically, produce); organic food (excluded from some proposed mandates); and "upstream" producers of inputs (e.g., bioengineered seed manufacturers). Also affected are the market's "downstream" producers (operations ranging from small organic farms to industrial "agribusinesses") and food manufacturers (e.g., Nabisco and CocaCola), as well as consumers.

According to Bonroy and Lemarié, "Two effects drive the economic consequences of the label. First, the label affects differentiation on the downstream market. The products are then differentiated in both the upstream and downstream markets, instead of only in the upstream market as in an unlabeled environment," the latter of which offers choice only for farmers and food manufacturers between GM or conventional seed and inputs-but not for consumers $(2012,351)$.

This increased choice results in very different production and purchasing patterns as information reaches the downstream market. Indeed, sources discuss both a "differentiation effect" and a "ranking effect" as affecting consumer and producer purchasing and production choices: "[A]s in a standard vertical differentiation model, information about quality differences tends to increase the price of each product [...] a 'differentiation effect”" (Bonroy and Lemarié 2012, 351). Consequently, "[b]y signaling qualities in the downstream [consumer] market, the label reverses the product ranking since all active producers will then prefer the highquality [non-modified] input, despite its higher cost [. . . ] a 'ranking effect"' (2012, 351). Labeling, then, changes downstream producer preferences, as those producers would prefer to spend more on inputs rather than report GMO use.

In terms of the consumer welfare effects of a label, "as consumer aversion increases [...] the inability of consumers to purchase the product that they prefer most results in larger and larger welfare losses" (Fulton and Giannakas 2004, 54). A label would then allow producers to sort consumers by willingness to pay in much the same way that a monopolist might maximize social surplus through price discrimination (2004, 54). Consumer-reported aversion to GMOs does, indeed, suggest that significant behavioral changes and potential welfare improvements could result from a labeling regime: recent polls have shown consumer attitudes toward GMO and GM foods to strongly support increased information availability. Results of an ABCNEWS.com survey demonstrated that 93 percent of respondents indicated a preference for GMO labeling, while 57 percent claimed that they would avoid purchasing GM foodstuffs if a labeling regime were in place (Langer 2012). Furthermore, research indicates a willingness to pay for labeling that varies across foodstuffs, ranging from 10 to 12 percent for cereal and 21.5 to 45 percent for olive oil (Norman 2007, 64; Moon and Balasubramanian 2003, 317). For those consumers concerned about the presence of GMOs, labeling represents an obvious opportunity for welfare improvements. Contrasting these apparent advantages, however, any labeling mechanism would also bring negative consequences to certain populations. A successful mechanism would need to speak to concerns of cost, equity, and market failure. For example, the costs of compliance with a labeling mandate would likely be passed on to consumers, reducing their welfare gains. According to Kalaitzandonakes and Lusk, "research from different countries suggests that instead of using GMO labels, most food companies prefer to buy more expensive non-GMO ingredients and pass the added costs to the consumers," avoiding labeling and sharing the burden of reformulation-related cost increases with consum- 
ers, much as producers and consumers would share a tax or subsidy $(2012,1)$. Bonroy and Lemarié further describe the negative consequences of the label for certain population segments, contending that "the benefit that downstream actors derive from consuming or producing the high-quality labeled product does not cover the loss of those who still consume or produce the low-quality product" (i.e., GM foods) but help to bear the cost burden of the label that allows other-potentially higher-income-consumers to shift their purchasing behaviors (2012, 353). While it is impossible to conclude whether research from other countries is generalizable to the US context, the economic logic of the distributional effects for low-income consumers seems very likely to apply. The logical implication of this argument is that lower-income consumers who continue to purchase GM goods may experience smaller, if any, welfare increases from a mandatory labeling regime than their higher-income counterparts who shift their purchasing decisions to non-GM goods.

Finally, there is the potentiality that labeling could lead to a collapse in the market for GM goods. According to Schmidt, "some surveys have shown that consumers are less likely to buy foods that they know are GM" (2005, A532). Should the label lead to market failure in the market for likely less-expensive GM products, there would be a loss-rather than a gainin choice for consumers. For example, "in the European Union and elsewhere, GM food with mandatory labeling has disappeared from the shelves" (Carter and Gruère 2003, 68). Similarly, "during a short period in the late 1990s, some food products in the EU were labeled as containing GM ingredients. According to Kalaitzandonakes and Bijam (2003) and Bernauer and Meins (2002), GM products then vanished in the EU" (Carter and Gruère 2003, 68).

To avoid altogether eliminating GM foodstuffs in the market, a success- ful labeling regime would need to set an appropriate product purity baseline, allowing the label to act very similarly to a grading mechanism: "Meeting the demand for differentiated food products requires a system that can credibly deliver such differentiated products to end users [. . . As Dimitri suggests,] grading of products and government inspections have long been used in agricultural markets" (Lapan and Moschini 2007, 769). This baseline should help to preserve the integrity of the markets for both GM and non-GM products-and avoid a net decrease in social welfare. It should also ensure that the label provides meaningful information to consumers-rather than causing all foods to be classified as containing GMOs (if the threshold is too low) or failing to alert consumers to the presence of GMOs (if the threshold is too high). While ensuring complete purity would be ideal for those persons wishing to avoid GMOs entirely, for realistic implementation to occur, trace quantities must be permissible (as they are in the vast majority of food regulations currently in place).

As discussed later, this process would be similar to other threshold calculations, such as those completed for the U.S. Department of Agriculture's (USDA's) National Organic Program (NOP) or the Food and Drug Administration's (FDA's) regulations of trans fats. For example, regulations that took effect in January 2006 "[require] the declaration of the amount of trans fat in a product, on a separate line directly below the statement for saturated fat; the declaration must express the amount of trans fat as grams per serving to the nearest $0.5 \mathrm{~g}$ increment below $5 \mathrm{~g}$ and to the nearest gram increment above 5 g. If a serving contains less than $0.5 \mathrm{~g}$, the trans fat content may be declared as zero" (Federal Register 2013). In the case of the European Union's GMO labeling regulations, "[t]he labeling requirements shall not apply to food containing material, which contains, consists of or is produced from GMOs in a proportion no higher 
than 0.9 percent of the food ingredients considered individually or food consisting of a single ingredient, provided that this presence is adventitious or technically unavoidable" (Directorate E 10). A threshold determination would be the result of scientific review by the FDA or the USDA's Economic Research Service (ERS), as well as public comment and expert input.

\section{The Label and Information Issues}

Akerlof's asymmetric information concept is one useful lens for understanding the labeling debate. Akerlof states that "quality may be represented, or it may be misrepresented. The purchaser's problem, of course, is to identify quality. The presence of people in the market who are willing to offer inferior goods tends to drive the market out of existence" (Akerlof $1970,495)$. In this case, the issue is about consumers' inability to identify food quality by discerning whether or not products contain GMOs, Akerlof's "inferior good." There are people with a willingness to pay higher prices for non-GM products, and there are others with a lower general willingness to pay who would prefer to continue to purchase lower-cost GM foods. If there is no consistent, market-wide, enforceable method for producers to sort consumers according to their willingness to pay, the lower-quality (in this case, GM) good will prevail, and the market for high-quality (in this case, non-GM) goods will collapse. When viewing the labeling debate through the lens of Akerlof's lemons model, the clear answer is to mandate labeling, thereby enabling consumers to self-select into groups according to their preferences and for producers to sell both GM and non-GM foodstuffs in their respective market-clearing quantities as demanded by consumers. As noted earlier, while this self-selection could threaten the market for GM goods, setting an appropriate product purity baseline should alleviate that concern.

Others who have written about GMO labeling in terms of asymmetric in- formation have considered non-GM foods as credence goods. According to Roe and Sheldon, "Increasingly, consumer goods are differentiated by process-attributes [...] However, many of these newly demanded process-attributes are not correlated with end-use attributes and, hence, an asymmetric information problem ensues: consumers cannot verify processattribute claims, even after lengthy inspection or consumption of the good" (2007, 1020). In other words, consumers cannot determine through observation whether or not a food product contains GMOs the way they could determine whether milk is skim or whole or whether a grape is red or green; even in consuming the product, the purchaser cannot determine whether or not it contains GMOs. This inability to "verify process-attribute claims" presents a problem because "if consumers cannot observe whether the product is GM or not, there is a risk that this uncertainty will eventually drive out what the consumers see as high-quality (GM-free) products, and only low-quality (GM) products will then prevail" (Carlsson, Frykblom, and Lagerkvist 2007, 153). Therefore, as in the traditional lemons model, consumers' inability to distinguish GMOs from nonGMOs, and thereby purchase according to their preferences, leads producers to provide only the low-quality good. When GMOs are considered a credence good, the surplus-maximizing policy is once again to mandate labeling, facilitating informed consumer decision-making. This informed consumer decision-making, which is facilitated by addressing the information asymmetry market failure, leads to self-selection according to willingness to pay for higher-priced non-GM versus likely harmless, lower-priced GM goods-preserving the demand and, therefore, integrity of the markets for both GM and non-GM goods.

\section{Libertarian Paternalism and the "Nudge"}

According to Louis Finkel, executive director of government affairs for 
the Grocery Manufacturers Association, "These labels could mislead consumers into believing that these food products are somehow different or present a special risk or potential risk" (Strom 2013). His concern suggests that labels could create a sort of libertarian paternalism, "nudging" consumers away from GM foods that have not been proven to represent any health-related or other threat. According to Thaler and Sunstein, "a policy counts as 'paternalistic' if it is selected with the goal of influencing the choices of affected parties in a way that will make those parties better off" (2003, 175). While the goal of the label would be to make it easier for consumers to act on their existing preferences rather than to change them, labeling could influence those preferences by signaling that GMOs are something to be avoided, similar to such already labeled food components as trans fats and cholesterol.

Thaler and Sunstein contend, however, that "planners are forced to make some design choices. A simple and important example is the selection of a 'default option' to determine what happens if an agent fails to choose for himself" (2003, 176). Citing Samuelson and Zeckhauser as well as Kahneman et al., the pair acknowledges, however, that "numerous experiments illustrate that there is a very strong 'status quo' bias" (Thaler and Sunstein 2003, 176). (For purposes of this analysis, the status quo is considered be the absence of labeling-with limited voluntary labeling of GM products, and the consequent intermingling of GM and non-GM products and limited voluntary labeling of GM products). Current voluntary labeling regimes provide inconsistent information, oftentimes to select consumer groupse.g., the more affluent consumers shopping at Whole Foods-without meaningful industry-wide oversight or ramifications for labeling violations beyond class action lawsuits related to false assertions (see the recent lawsuits against Naked Juice). Therefore, their effect is not cohesive or widespread enough to accomplish the industry-wide regulation in the way that mandatory labeling would.

The "nudge" of the label, then, could very well drive some consumers who would otherwise opt for the (likely less expensive) labeled GM goods to purchase (likely more expensive) "default" non-GM alternatives-decreasing their surplus. That said, if GM food products were shown in future years to pose an as-yet undiscovered health threat, a failure to nudge less-informed or lower-income populations toward the non-GM foods could be perceived as reserving the "high quality" food for high-income individuals, an equity issue itself. Not providing these populations with the same information suggests serious negative distributional impacts.

If it is impossible to avoid a nudge, as Thaler and Sunstein posit, the label seems to create the more equitable one since a non-labeling regime in an undifferentiated market inevitably nudges both consumers and producers toward "lower quality" GM food with lower costs of production and makes conventionally grown food a near-unobtainable luxury. Indeed, "Some kind of paternalism is likely whenever [. . . ] institutions set out arrangements that will prevail unless people affirmatively choose otherwise. In these circumstances, the goal should be to avoid random, arbitrary, or harmful effects and to produce a situation that is likely to promote people's welfare, suitably defined" (2003, 179). If welfare is defined as the ability of all consumers, across socioeconomic strata and geographic locations, to making informed, utility-maximizing food purchasing decisions (and to have nutritious, GM or non-GM foods available to them where they live), a label would help to produce such a situation.

\section{Implementation of a Labeling Regime}

Based on the conclusions suggested through the lenses of both Akerlof's concept of asymmetric information, viewed through the traditional lemons model and 
the credence goods analyses, as well as Thaler and Sunstein's "nudge," the socially optimal policy would be to mandate labeling of all foodstuffs containing GMOsgiven the establishment of an appropriate product purity baseline, as discussed previously, to avoid failure in the market for GM foodstuffs. This recommendation also assumes that increasing consumer choice would increase individual utility-as in the rational model-rather than diminish it through creation of an excessive number of alternatives-as in the behavioral model.

The design of the label would be an important consideration in implementing the labeling regime, as it could significantly affect the extent to which the label provides a nudge to consumers. According to research on the use of color in marketing, "People make up their minds within 90 seconds of their initial interactions with either people or products. About 62-90 percent of the assessment is based on colors alone. So, prudent use of colors can contribute not only to differentiating products from competitors, but also to influencing moods and feelings-positively or negatively-and therefore, to attitude towards certain products" (Singh 2006, 783). The label should therefore be designed to be visible without creating strongly negative reactions that nudge consumers at the margin, whose utility would likely not be increased in switching to potentially higher-priced non-GM food goods.

The proposed mandatory labeling regime could be administered by the USDA, which already administers the NOP, and could be completed by thirdparty certifiers similar to the method used for the NOP. A new office would likely need to be created for purposes of administering the GMO labeling program.

Such a labeling regime could create significant administrative burdens, as in current US operations, "both GM and conventionally grown nonorganic crops can wind up in the same containers as they make their way through distribution channels" (Schmidt 2005, A532). The costs of creating new systems to segregate the GM and non-GM foodstuffs could be significant. Some research indicates that the marketing costs alone associated with separating GM from conventional crops could approach " $\$ 0.22 /$ bushel for corn and $\$ 0.54 /$ bushel for soybeans [. . . ] from country elevator to export elevator" (Moon and Balasubramanian 2003, 318). Such initial costs, however, are an inevitable piece of any consumer-protecting regulation and would be more or less fixed, therefore diminishing in the long-term as compliance became a part of regular operations. Nonetheless, the USDA would need to conduct concerted outreach to farmers and manufacturers in preparation for the immediate economic impacts of the implementation of a labeling program.

Monetary costs would also decrease for consumers in the long term: "The presence of labeling can have key implications for the marketplace [...] The market structure is fundamentally altered in that two firms rather than one enter when labeling is present and labeling costs are not too high. Consumers are given greater choice, and competition between firms helps push down prices and, hence, improves consumer welfare" (Roe and Sheldon 2007, 1030). As suggested previously, mandated GMO labeling should increase surplus.

When determining the trace quantity of GMO inputs that can be included within the purity baseline, it will be important for the FDA or the ERS to conduct focused analysis to balance the integrity preservation goals of the label with producer compliance burden. According to Roe and Sheldon, "The government risks pushing out the high-quality good if the government-chosen standard is too high or too low to yield positive profits for the high-quality producing firm" $(2007,1031)$. Too stringent a limit on the quantity of GM inputs would make it unprofitable for producers to re-formulate their products or otherwise alter their operations to avoid 
the label, thereby reducing the producer (and consumer) choice and resultant welfare benefits.

\section{Consequences of a GMO Labeling Regime}

While a GMO labeling regime should increase social surplus, some populations would see negative effects. In particular, should labeling increase the price of food overall or make non-GM products more expensive (a very real possibility), low-income individuals would bear a disproportionate burden. This inequity would result because "lower income households across the United States spend a larger portion of their income on food than higher income households. Lower income households also spend most of these dollars for food at home" (Kalaitzandonakes and Lusk 2012). This burden would also fall on more elderly members of the population, as "similar trends exist for older relative to younger consumers" (Kalaitzandonakes and Lusk 2012). To address this issue, the USDA should work to ensure, through methods similar to those used to forge partnerships with farmers' markets guaranteeing availability of healthy foods for low-income individuals, that those participating in the Supplemental Nutrition Assistance Program (SNAP) and related initiatives targeting low-income and elderly populations have equal access to clearly labeled, federally regulated nonGM products in all grocery outlets. That being said, as discussed previously, labeling could introduce new competition into the market for non-GM foodstuffs, actually lowering prices for consumers and thereby largely alleviating this concern.

Another indirect effect of the labeling regime would fall on competition in the upstream market (e.g., seed production and purchase). Farmers know that products containing GMOs will sell for a lower price in the consumer market than nonGM foods, and they make their own seed purchasing and planting decisions accordingly (Bonroy and Lemarié 2012, 356). In the long-term, this change in preferences could threaten the supply and existence of the market for GM foods. Because GM foods do have important qualities that justify their continued existence and development (e.g., pest resistance, flood resistance, and high crop yields), ERS should consider ways to incentivize the continued research and development of bioengineered agricultural products through research funding, grants, and similar vehicles.

\section{Conclusion}

From their introduction in the late 1990s, foods containing GMOs have sparked debate among consumer advocates, economists, and policymakers. To address consumer concerns, as well as market failures inherent in the current system of selling GM and non-GM foods alongside each other with no signal of quality (in line with Akerlof's lemons model), many have suggested-and the European Union and Japan have implemented-ongoing mandatory labeling regimes. More recently, Californians voted against Proposition 37 and Washingtonian State residents voted against Initiative 522 , both of which would have created a labeling mandate. In contrast, Whole Foods announced in early 2013 its intent to require GMO labeling in its stores by 2018 . After considering the economic arguments for and against GMO labeling, this paper recommends implementation of a labeling regime in the US to facilitate informed consumer decision-making for consumers of all income levels and to maximize social surplus. It also recommends that the USDA, the suggested administrator of the labeling program, address potential inequities and negative consequences that could arise from the regime. 


\section{References}

Akerlof, George A. 1970. “The Market for 'Lemons': Quality Uncertainty and the Market Mechanism. The Quarterly Journal of Economics 84(3): 488-500. Accessed May 3, 2013. http://links.jstor.org/sici?sici=00335533\%28197008\%2984\%3A3\%3C488\%3ATMF\%22QU\%3E2.0.CO\%3B2-6.

Barclay, Eliza, and Martin Kaste. 2013. "Washington State Says 'No" To GMO Labels." The salt: What's on Your Plate, November 7, 2013. Accessed December 1, 2013. http://www.npr.org/blogs/thesalt/2013/11/o6/243523116/washingtonstate-says-no-to-gmo-labels.

Bonroy, Olivier, and Stéphane Lemarié. 2012. "Downstream Labeling and Upstream Price Competition.” European Economic Review 56(3): 347-360. Accessed April 25, 2013. doi: 10.1016/j.euroecorev.2011.10.003.

Carlsson, Fredrik, Peter Frykblom, and Carl Johan Lagerkvist. 2007. "Consumer Benefits of Labels and Bans on GM Foods-Choice Experiments with Swedish Consumers." American Journal of Agricultural Economics 89(1): 152-161. Accessed April 23, 2013. http://www.jstor.org/stable/4123569.

Carter, Colin A., and Guillaume P. Gruère. 2003. "Mandatory Labeling of Genetically Modified Foods: Does It Really Provide Consumer Choice?” AgBioForum: The Journal of Agrobiotechnology Management \& Economics 6(1\&2): 68-70. Accessed April 24, 2013. http://www.agbioforum.org/v6n12/v6n12a13-carter.htm.

Directorate E. 2006. "Labelling: competitiveness, consumer information and better regulation for the EU: A DG SANCO Consultative Document." The European Commission. Accessed December 1, 2013. http://ec.europa.eu/food/food/labellingnutrition/betterregulation/competitiveness_consumer_info.pdf.

Federal Register. 2013. "Tentative Determination Regarding Partially Hydrogenated Oils; Request for Comments and for Scientific Data and Information." $78 \mathrm{Fed}$ eral Register 67169 (8 November 2013), 67168-67175. Accessed December 1, 2013. https://federalregister.gov/a/2013-26854.

Fulton, Murray, and Konstantinos Giannakas. 2004. "Inserting GM Products into the Food

Chain: The Market and Welfare Effects of Different Labeling and Regulatory Regimes.” American Journal of Agricultural Economics 86(1): 42-60. Accessed April 23 2013. http://www.jstor.org.proxygw.wrlc.org/stable/3697873.

Jain, Priyanka. 2011. "Genetically modified organisms.” In Green Food: An A-to-Z Guide, edited by D. Mulvaney and P. Robbins, 217-224. Thousand Oaks: SAGE Publications, Inc. Accessed December 1, 2013. doi: http://dx.doi.org/proxygw. wrlc.org/10.4135/9781412971874.n75.

Kalaitzandonakes, Nicholas, and Jayson Lusk. 2012 "Who Will Cover the Costs of California's Prop. 37?” Forbes, November 2. Accessed November 4 2012. http:// www.forbes.com/sites/realspin/2012/11/02/who-will-cover-the-costs-ofcalifornias-prop-37/.

Langer, Gary. 2012. "Poll: Skepticism of Genetically Modified Foods." ABCNEWS. com, June 19. Accessed March 18, 2014. http://abcnews.go.com/Technology/ story?id=97567

Lapan, Harvey, and GianCarlo Moschini. 2007. "Grading, Minimum Quality Standards, and the Labeling of Genetically Modified Products.” American Journal of Agricultural Economics 89(3): 769-783. Accessed July 7, 2013. http://www. card.iastate.edu/faculty/profiles/giancarlo_moschini/lapan-moschini-ajaeaugust-07.pdf. 
Mellon, Margaret, and Jane Rissler. 2004. "Gone to Seed: Transgenic Contaminants in the Traditional Seed Supply." Union of Concerned Scientists. Accessed December 1 2013. http://www.ucsusa.org/assets/documents/food_and_agriculture/ seedreport_fullreport.pdf.

Moon, Wanki, and Siva K. Balasubramanian. 2003. "Willingness to Pay for Non-biotech Foods in the U.S. and U.K." The Journal of Consumer Affairs 37 (2) (Winter): 317-339. Accessed October 29, 2013. http://search.proquest.com/docview/195 908469/1416B48069877A6C3E/7?.

Norman, Christopher A. 2007. "The effects of benefit information on labels and subjective knowledge on willingness to pay for genetically modified foods." Ph.D. diss., University of Guelph (Canada). Accessed October 29, 2013. http://search.proquest.com/docview/304847163/1416B48069877A6C3E/3?.

Roe, Brian, and Ian Sheldon. "Credence Good Labeling: The Efficiency and Distributional Implications of Several Policy Approaches." American Journal of Agricultural Economics 89(4): 1020-1033. Accessed April 24, 2013. http://www. jstor.org/discover $/ 10.2307 / 4492877$ ?uid=3739936\&uid=2\&uid=4\&uid=3739 $256 \&$ sid $=21102236779727$.

Schmidt, Charles W. 2005. "Genetically Modified Foods: Breeding Uncertainty." Environmental Health Perspectives 113(8): A526-533. Accessed April 23, 2013. http://www.jstor.org.proxygw.wrlc.org/stable/3436337.

Singh, Satyendra.2006. "Impact of color on marketing." Management Decision 44(6): 783-789. Accessed October 20, 2013. doi: 10.1108/00251740610673332.

Strom, Stephanie. 2013. "Major Grocer to Label Foods With Gene-Modified Content.” New York Times, March 8. Accessed May 3, 2013. http://www.nytimes. com/2013/o3/o9/business/grocery-chain-to-require-labels-for-geneticallymodified-food.html.

Thaler Richard H., and Cass R. Sunstein. 2003. "Libertarian Paternalism.” The American Economic Review 93(2): 175-179. Accessed April 28, 2013. http://www.jstor.org/stable/3132220.

Washington State Initiative Measure No. 522. AN ACT Relating to disclosure of foods produced through genetic engineering; adding a new chapter to Title $70 \mathrm{RCW}$; and prescribing penalties. Filed June 29, 2012. Accessed September 14, 2013. http://sos.wa.gov/_assets/elections/initiatives/FinalText_285.pdf. 
Katherine Hartman is a second year student in the George Washington University's Master of Public Administration program. She has worked in the statistical and science policy branch of White House Office of Management and Budget's Office of Information and Regulatory Affairs, as well as the George Washington Institute of Public Policy and the Consumer Financial Protection Bureau, during her graduate career. On campus, Katherine has served as the Trachtenberg Student Organization's professional development co-chair and co-founder of the Women's Leadership Fellows program. She plans to work in federal management consulting after graduation.

The author thanks Dr. Gerald Brock, for whose course she wrote this paper and who encouraged her to submit her draft to Policy Perspectives. She also thanks Dr. Stephanie Riegg Cellini, in whose class she first encountered GMO labeling, as well as her responsive faculty reviewer (and fellow Maroon) Dr. Marvin Phaup. On the Policy Perspectives editorial team, the author thanks Laura Saltzman, her thoughtful editor, as well as Editor-in-Chief Brandon Kruse and Managing Editor Tanya Harris Joshua for their dedication and guidance. On a personal note, the author thanks her mentors at GWIPP, OMB, and the Trachtenberg School of Public Policy and Public Administration for their active encouragement, as well as the patient friends who continue to associate with her despite innumerable conversations about food. Finally, the author thanks her wonderful family, who have given her the greatest unconditional love and support for which a person could wish-and muddled through the many difficult culinary experiences to which she has subjected them from early childhood. 